\title{
Landscape heterogeneity shapes taxonomic diversity of non-breeding birds across fragmented savanna landscapes
}

Alison Ke, 1,2凶

Phone 215-582-4848

Emailalisonke@berkeley.edu

Muzi D. Sibiya, 3

Emailmuzisibiya07@gmail.com

Chevonne Reynolds, 1,4,5,7

Email chevonne.reynolds@wits.ac.za

Robert A. McCleery,

Email ramccleery@ufl.edu

Ara Monadjem, 3,6

Emailara@uniswa.sz

Robert J. Fletcher, $\mathrm{Jr}^{1}$

${ }^{1}$ Department of Wildlife Ecology and Conservation, University of

Florida, Gainesville, FL, 32611-0430 USA

2 Department of Environmental Science, Policy and Management, University of

California at Berkeley, Berkeley, CA, 94720 USA

3 Department of Biological Sciences, University of

Swaziland, Kwaluseni, M201 Swaziland

4 Percy FitzPatrick Institute of African Ornithology (PFIAO), DST/NRF Centre of Excellence, University of Cape Town, Rondebosch, Cape Town, 7701 South Africa

5 Statistics in Ecology, Environment and Conservation, Department of Statistical Sciences, University of Cape Town, Rondebosch, 7701 South Africa 
6 Department of Zoology \& Entomology, Mammal Research Institute, University of Pretoria, Pretoria, South Africa

7 Present Address: School of Animal, Plant and Environmental

Sciences, University of the Witwatersrand, Braamfontein, 2001 South Africa

Received: 11 July 2017 / Accepted: 23 May 2018

\section{Abstract}

There is an ongoing need to integrate agricultural production with wildlife conservation to maintain biodiversity, especially in developing countries. The landscape heterogeneity hypothesis identifies a potential means for promoting biodiversity in agricultural landscapes by emphasizing that increasing heterogeneity can increase biodiversity. However, the importance of landscape heterogeneity relative to habitat amount and vegetation structure is poorly understood, particularly regarding the relative importance of different components of landscape heterogeneity. We investigated how taxonomic, functional, and phylogenetic diversity of non-breeding birds responded to two components of landscape heterogeneity, compositional and configurational heterogeneity, and compared the importance of the landscape heterogeneity hypothesis relative to the habitat amount hypothesis and vegetation structural heterogeneity hypothesis. To do so, we conducted point counts at 80 plots across 16 landscapes during June-July 2016 in northeastern Swaziland, a sub-tropical savanna. We found a positive effect of landscape heterogeneity on taxonomic diversity, but no effect of habitat amount or vegetation structure. In contrast to taxonomic diversity, we found a positive trend between the amount of savanna habitat and phylogenetic diversity. In agricultural mosaics in subtropical savannas, conservation value may be created if landscape compositional heterogeneity, landscape configurational heterogeneity, and large areas of habitat are incorporated into land planning. Our findings show that it is important to use multiple measures of diversity in conjunction with various landscape and habitat measures when designing conservation management strategies.

\section{Keywords}

Bird diversity

Habitat amount hypothesis 
Heterogeneity hypothesis

Landscape composition

Landscape configuration

Vegetation structural heterogeneity

Communicated by David Hawksworth.

\section{Electronic supplementary material}

The online version of this article (https://doi.org/10.1007/s10531-018-1561-7) contains supplementary material, which is available to authorized users.

\section{Introduction}

The intensification and expansion of agriculture to support a rapidly growing human population has accelerated the decline of biodiversity (Freedman 2014). Although the total area dedicated to nature reserves has increased 500\% during the past three decades (Wittemyer et al. 2008), only $12.5 \%$ of terrestrial land is protected (Watson et al. 2014), while comparatively $40 \%$ of land surface is occupied by croplands and pastures (Foley et al. 2005). The most dramatic agricultural land-use change is currently occurring in developing nations (Pickett et al. 2012), which also tend to contain most of the world's biodiversity (Brashares et al. 2001). AQ1

In the developing world, agriculture is commonly interspersed with human settlements and natural areas in a mosaic of different land uses (Wright et al. 2012). These heterogeneous landscapes provide a means for testing whether the promotion of heterogeneity as predicted under the landscape heterogeneity hypothesis is useful in maintaining biodiversity in agricultural landscapes (Fahrig et al. 2011). Landscape heterogeneity is typically comprised of two components that can affect biodiversity: (i) compositional heterogeneity, defined as the number of land-cover types present and their relative proportions, and (ii) configurational heterogeneity, defined as the spatial patterning of the different land-cover types across the landscape (Gustafson 1998; Fahrig and Nuttle 2005; Fahrig et al. 2011). Increased compositional heterogeneity may promote biodiversity through landscape complementarity, whereby different cover types possessing particular resources are dominated by different sets of species (Dunning et al. 1992; Haase et al. 2017). In contrast, increased configurational heterogeneity may positively influence biodiversity because fragmentation of land-cover increases the variability of available resources that may prevent exclusion by a single superior competitor 
(Knapp et al. 1999; Olff and Ritchie 2002). There is empirical evidence supporting the positive relationship between biodiversity and heterogeneous landscapes (Poulsen 2002; Benton et al. 2003; Neumann et al. 2016). However, the relative importance of each component for maintaining diversity is unclear (but see Reynolds et al. 2018), especially when considering multiple dimensions of diversity and community composition.

Biodiversity can be conceptualized and quantified in many ways that capture different aspects of community composition (Safi et al. 2011). Accordingly, efforts to understand variation in biodiversity should use a suite of metrics that may be important in shaping community change (Devictor et al. 2010). The most common measure of biodiversity is taxonomic diversity (TD), which refers to the number and/or relative proportion of species in a community. Alternatively, measures of functional diversity (FD) account for the diversity of morphological, physiological, and ecological traits within biological communities (Petchey et al. 2004; Petchey and Gaston 2006) and can be better at explaining ecosystem functioning than classical measures of TD (e.g. species richness, Simpson's diversity index) (Devictor et al. 2010). Measures of phylogenetic diversity (PD) account for the phylogenetic difference between species in a community (Faith 1992), explicitly measuring species differences rather than species numbers or traits. Greater PD has been found to be correlated with higher ecosystem stability and productivity (Cadotte et al. 2012; Cadotte 2013). Diversity can also be measured at different scales with alpha and beta diversity. Alpha diversity represents a point metric of the number and evenness of species in a local area, while beta diversity measures the turnover of species across space and the stability of species composition (Pimm and Gittleman 1992). Both types of diversity are important to understanding spatial patterns of communities across landscapes. Investigating the effects of landscape heterogeneity on multiple measures of biodiversity may provide a more holistic analysis of the role of landscape heterogeneity in promoting biodiversity.

While there has been recent interest in understanding effects of landscape heterogeneity on biodiversity, it has long been known that biodiversity is often closely correlated with structural heterogeneity of vegetation at fine-scales, i.e. the vegetation structural heterogeneity hypothesis (e.g. MacArthur 1958; Lesak et al. 2011; Mulwa et al. 2012; Culbert et al. 2013). Despite being well studied, there remain contradictory conclusions about the relationship between structural heterogeneity and species diversity depending on the taxonomic group, vegetation structure, and the spatial scale under consideration (Tews et al. 2004). Alternatively, the habitat amount hypothesis predicts that species diversity is a function of the 
amount of suitable habitat in the landscape (Preston 1962; Fahrig 2013). Some studies have reported positive effects of habitat amount within a local area on species richness in host-parasitoid communities and marsupials (Püttker et al. 2013; Coudrain et al. 2014), yet other studies have found no support for this hypothesis, and it is currently unclear how important this hypothesis is for explaining biodiversity patterns (Haddad et al. 2017). Comparing these alternative hypotheses is particularly important for effective conservation planning in the developing world where agricultural ecosystems are rapidly fragmenting untransformed, native habitats.

Here we investigate how TD, FD, and PD of non-breeding birds respond to landscape heterogeneity in a savanna landscape mosaic characterized by natural areas amidst a range of other land uses, including subsistence farming, human settlement, and commercial sugarcane farming. Birds are useful for understanding the factors influencing biodiversity because they are diverse, well studied, and sensitive to environmental gradients (de Lima et al. 2013; Seymour et al. 2015). Our objectives were to: 1) compare the strength of the components of landscape heterogeneity to the alternate hypotheses of habitat amount and vegetation structural heterogeneity; and, 2) evaluate which component of landscape heterogeneity, composition or configuration, best predicted non-breeding bird TD, $\mathrm{FD}$, and PD.

\section{Methods}

\section{Study area}

We addressed our objectives in the north-east of Swaziland (Fig. 1a), within a study area of approximately $60 \mathrm{~km} \times 100 \mathrm{~km}$ of sub-tropical savanna delineated by the Lowveld elevational region. This area forms a part the Maputaland-PondolandAlbany biodiversity hotspot, recognized for its high biodiversity and endemism (Critical Ecosystem Partnership Fund 2010; Smith et al. 2008). The average monthly temperature ranges from $18{ }^{\circ} \mathrm{C}$ in July to $26^{\circ} \mathrm{C}$ in January, and the mean annual rainfall is $550-725 \mathrm{~mm}$ (Goudie and Williams 1983). The vegetation is dominated by fine-leaved woodland typically comprising various species of acacias (Vachellia and Senegalia) on basaltic soils in the east, while the granitic soils in the west support broad-leaved woodland typically comprising Combretum and Terminalia species (Sweet and Khumalo 1994). The dominant land-uses in the region are commercial sugarcane farming, rural and peri-urban developments and associated subsistence agriculture, cattle ranching, and protected areas. 
Fig. 1

a Map of Swaziland with the extent of the study area. b Map of the study site and location of sampling landscapes in the lowveld of Swaziland. The $30 \mathrm{~m} \times 30 \mathrm{~m}$ landcover raster emphasizes large variation in the amount and arrangement of commercial agriculture, woodland, savanna, and subsistence agriculture. Numbered black circles represent sampling landscapes. c A typical $2 \mathrm{~km}$ radius sampling landscape containing five survey plots within a $550 \mathrm{~m} \times 550 \mathrm{~m}$ sampling grid (with plots centered on the corners of a $500 \mathrm{~m} \times 500 \mathrm{~m}$ grid). The sampling grid is not drawn to scale 

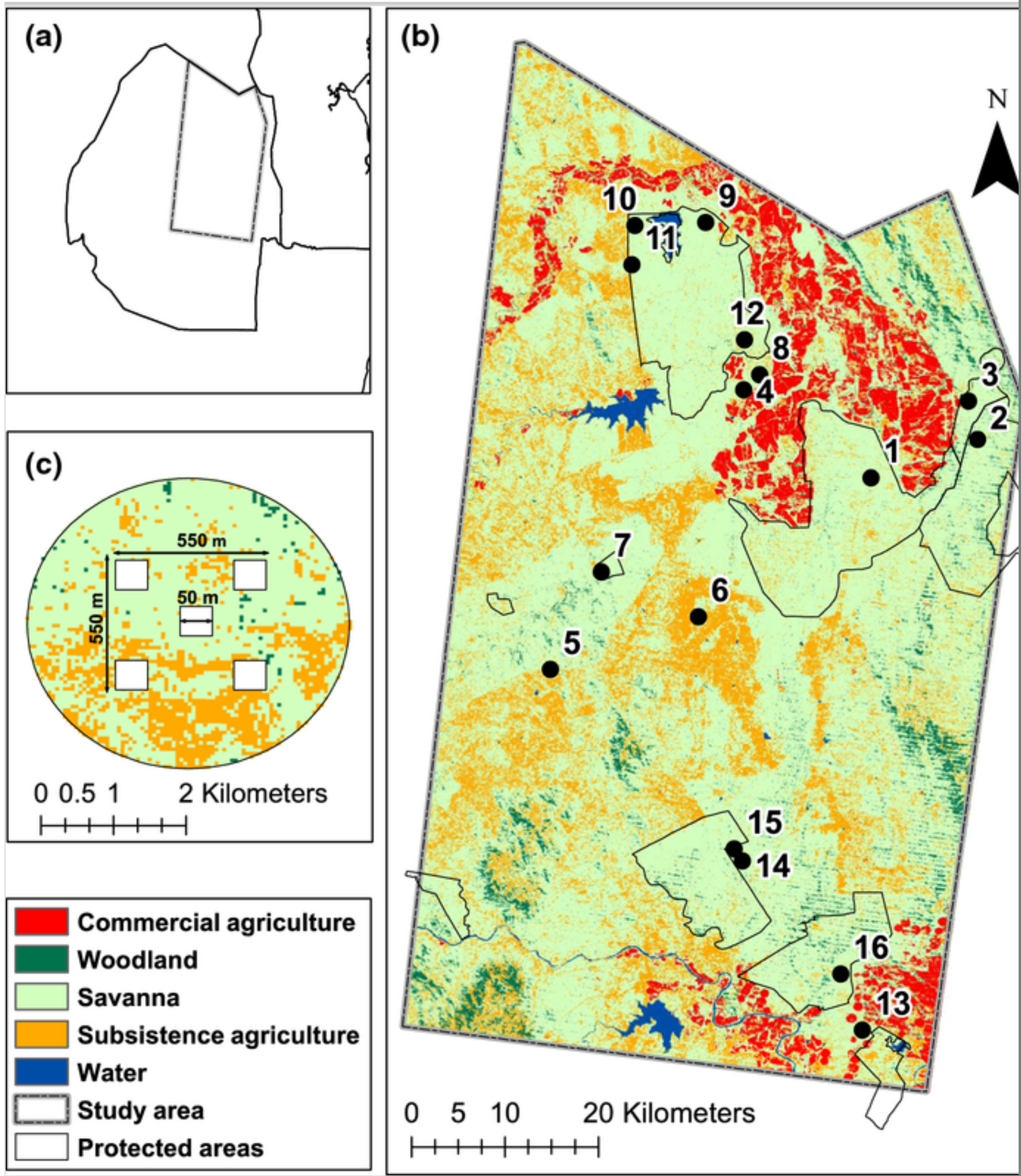

\begin{tabular}{|l|}
\hline Commercial agriculture \\
Woodland \\
$\square$ Savanna \\
Subsistence agriculture \\
Water \\
$\square$ Study area \\
$\square$ Protected areas \\
\hline
\end{tabular}

(b) 
fine-resolution land-cover dataset for our study site, we used Google Earth Engine (GEE), an online GIS platform for analyzing large geospatial datasets (Google Earth Engine Team 2015). In GEE we performed supervised pixel-based classification on Landsat 8 annual TOA-corrected percentile composite imagery (Goldblatt et al. 2016). We used a classification and regression tree (CART) classifier to predict the occurrence of the land-cover types across the study area at a $50 \mathrm{~m}$ x $50 \mathrm{~m}$ resolution (Gislason et al. 2006; Goldblatt et al. 2016). To train the classifier we provided user-defined points and polygons of known land-cover. Our final training dataset consisted of over 3600 training points and 155 training polygons from five land-cover classes: commercial sugarcane agriculture, subsistence agriculture and rural villages, savanna, woodland, and open water (Fig. 1b). We considered savanna habitat to be both acacia savanna and broadleaved woodland and combined various types of savanna differing in floristics and management type, lumping savannas within and outside protected areas. The overall validity of the classification was $79.15 \%$. The correct classification of training and test datasets for each land-cover class was $80.78 \%$ for commercial agriculture, $67.92 \%$ for subsistence agriculture, $87.04 \%$ for savanna, $99.22 \%$ for water and $71.65 \%$ for woodland. The relative proportions of land cover types in our study region were $70 \%$ savanna, $19 \%$ communal lands, $6 \%$ agriculture, $4 \%$ woodland, and $1 \%$ water.

Quantifying and sampling composition and configuration gradients We used functions from the raster and SDMTools packages in R to implement a moving-window analysis (R Core Team 2000; VanDerWal et al. 2014; Hijmans 2016 ) to identify gradients in landscape composition and configuration (Wagner and Fortin 2005). We set a window with a $2 \mathrm{~km}$ radius, a spatial scale at which previous studies have found significant responses of birds (Buhning-Gaese 1997; Heikkinen et al. 2004; Neumann et al. 2016). We restricted sampling landscapes to be centered on cells that were surrounded by at least a $500 \times 500 \mathrm{~m}$ buffer of savanna because we were interested in the effects of landscape heterogeneity on biodiversity in savanna patches, which we assumed was the suitable habitat for savanna-restricted bird species of interest (Monadjem 2005; Sirami and Monadjem 2012) (Fig. 1b). Within the $2 \mathrm{~km}$ buffer we calculated: the Shannon diversity index of land-cover types (SHDI), land-cover richness (LCR), total edge length between land-cover classes (TE), the total number of patches (NP), large patch index (LPI), patch cohesion (COHESION) and patch division (DIVISION). The metrics SHDI and LCR represent the diversity of land cover types, which may affect bird diversity through the different resources provided by each cover type. The metrics NP, LPI, 
COHESION, and DIVISION are measures of complexity of arrangement and connectivity of patches, which may affect bird species that respond to factors such as habitat connectivity, patch sizes, or edge effects. Specifically, LPI represents the area of the largest patch type within the buffer divided by the total area of the buffer, COHESION represents the physical connectedness of the patches in the buffer, and patch division measures the probability that two $50 \mathrm{~m}$ x $50 \mathrm{~m}$ cells in the buffer are not within the same patch.

To create two orthogonal components of landscape heterogeneity representing compositional heterogeneity and configurational heterogeneity, we used principal components analysis (PCA) with functions from the psych package (Revelle 2014). We chose the commonly used SHDI and LCR indexes to represent compositional heterogeneity and we used the remaining landscape metrics as measures of configurational heterogeneity, which represented key components of landscape configuration such as edge, subdivision, and connectivity (Cushman et al. 2008; Fahrig et al. 2011). We then ranked all cells based on their PCA value for compositional and configurational heterogeneity. With these rankings, we used stratified sampling to select 16 sampling landscapes across gradients of compositional and configurational heterogeneity. We randomly chose sampling landscapes (subject to land access approval) that were in the upper and lower quartiles of compositional and configurational heterogeneity $(<25 \%$ and $>75 \%$ for each combination) and supplemented this sampling with locations of moderate heterogeneity (25-75\% quantile). Thus, for our study region, we sampled landscapes characterized by (1) both high, (2) both low, (3) high and low, (4) low and high, and (5) moderate compositional and configurational heterogeneity. We stratified each of these categories by latitude (by creating three latitudinal blocks in the landscape) to control for potential biases within our extensive $6000 \mathrm{~km}^{2}$ study site.

While this design maximized the independence of sampling compositional and configurational gradients in the region, there was still a weak correlation between the compositional and configurational components in these sampled landscapes (Pearson's $r_{\mathrm{p}}=0.48 ; \mathrm{p}$ value $=0.06$ ). The selected landscapes were placed at least $1 \mathrm{~km}$ apart to reduce the spatial autocorrelation between sampling landscapes (Fig. 1b).

\section{Bird counts and biodiversity metrics}

Non-breeding birds are often less emphasized and more poorly understood than breeding birds in many regions of the world. We focused on non-breeding birds 
because in the non-breeding season, the primary activities are foraging.

Consequently, our results focus on how landscape heterogeneity impacts the use of habitats for foraging by non-breeding birds. During the breeding season, both foraging and breeding site limitations can affect decisions, and in this region a large portion of the community during the breeding season is non-breeding migrants, complicating the interpretation of community-level responses.

We centered a $500 \mathrm{~m} \times 500 \mathrm{~m}$ grid at each selected sampling landscape in the savanna land-use. Each grid consisted of five $50 \mathrm{~m}$ radius sampling plots with a plot centered at each of the four corners of the grid and one at the center of the grid. This sampling design resulted in 80 plots across 16 sampling landscapes (Fig. 1c). Point counts were used to sample the non-breeding bird community during the dry season, June-July 2016. We repeated point counts at each plot four times over four consecutive days. Point counts were conducted by experienced observers (MS, CR, and AM) and entailed recording all birds seen or heard for 10 min within a $50-\mathrm{m}$ radius of the center of each plot. To avoid observer bias in bird community sampling, we randomized the sampling order of the plots and alternated observers between plots on consecutive days. All point counts occurred between dawn and $3.5 \mathrm{~h}$ after sunrise and were not conducted under rainy or windy conditions to maximize detection. We excluded raptors, waterbirds, shorebirds, nocturnal birds, and flyovers from the analysis because they select habitat on a larger scale than the size of our sampling plots.

To determine the effects of the different components of landscape heterogeneity on taxonomic diversity (TD), we calculated bird species richness and diversity (alpha diversity), as well as community dissimilarity (beta diversity) within sampling landscapes. To account for imperfect detection when estimating species richness, we used the vegan package (Oksanen et al. 2013) to calculate the first-order jackknife, which reduces bias in species richness estimates by adjusting counts of species by the number of 'singletons' observed (i.e., the number of species only observed once). The rationale is that if there are many singletons, raw counts of the number species are likely underestimates, while if there are few to no singletons, counts of species are more likely to reflect true species richness for a site (Smith and van Belle 1984; Walther and Martin 2001). The jackknife estimator of species richness was normally distributed $(\mathrm{W}=0.985, p=0.448)$. Simpson's index of diversity was used to test for an effect on species evenness (DeJong 1975) as it was considered normal ( $\mathrm{W}=0.988, p=0.673$ ), whilst Shannon's diversity was nonnormal ( $\mathrm{W}=0.950, p=0.0033$ ). Finally, to test for differences in community composition between the sampling landscapes we calculated the Bray-Curtis 
distance matrix as our metric for community dissimilarity. All TD metrics were calculated with functions from the vegan package in R (R Core Team 2000;

Oksanen et al. 2013).

To measure functional diversity of biodiversity, we used characteristics of diet, habitat preference, morphology, and reproduction for each bird species (Table S1) to calculate functional dispersion (hereafter FD), which represents the dispersion in trait combination abundances in a community. Food type, foraging location, habitat preference, and nest site substrates pertain to resource use and habitat requirements. Morphology and average clutch size reflect physiological constraints related to foraging and reproductive effort, respectively. Because we sampled non-breeding birds, we also ran the same analysis excluding reproductive traits, which did not change the results. We obtained information about functional attributes from Wilman et al. (2014) and Hockey et al. (2005).

To calculate FD for each plot, we first calculated the Gower dissimilarity matrix of the functional traits using the gowdis function in the $F D$ package (Laliberté et al. 2014). Then, we calculated functional dispersion using the $d b F D$ function in the $F D$ package (Laliberté et al. 2014). Functional dispersion is defined as the mean distance in multidimensional trait space of individual species to the centroid of all species (Laliberté and Legendre 2010). Functional dispersion is a desirable metric as compared to other functional metrics (e.g. functional richness and evenness) because it measures the dispersion of species in a trait space (unlike functional evenness and divergence), is not as sensitive to outliers as functional richness, and it weights distances of individual species by their relative abundances (Laliberté and Legendre 2010). We implemented a null model approach to determine how the observed FD in each plot differed from the expected FD (Flynn et al. 2009). We shuffled the species labels in the distance matrix and calculated functional dispersion 999 times while keeping species richness constant. We used the standardized effect size of our observed FD in comparison to the 1000 FD measures as our final FD metric.

To measure phylogenetic diversity of biodiversity, we used the phylogeny of the world's bird species from Jetz et al. (2012) to calculate mean pairwise phylogenetic distances between species (hereafter PD), which represents how widely species are evolutionarily distributed across clades in a community. We generated 1000 trees based on the "Hackett All Species" backbone, which we chose because it uses a more extensive genomic scope of loci in the phylogeny construction than the "Ericson" backbone (Jetz et al. 2012). We implemented the cophenetic function in 
the ape package (Paradis et al. 2004) to generate pairwise phylogenetic distance matrices corresponding to each of the 1000 phylogenetic trees. We then took the mean of the pairwise distance matrices, resulting in one distance matrix. We chose mean pairwise distance to represent PD because it reflects phylogenetic structure across the entire phylogenetic tree (unlike mean nearest taxon distance), and is independent of species richness (unlike the sum of total branch lengths) (Winter et al. 2013). We used a null model method to determine how the observed PD in each plot differed from the expected PD. We used the ses.mpd function in the picante package (Kembel et al. 2010) to calculate a standardized effect size of the PD metric for each plot. We kept species richness constant, accounted for species abundances by weighting the mean nearest taxon distances by abundance, and shuffled species labels 999 times. All analyses were conducted in R Version 3.2.4 (R Core Team 2000).

\section{Landscape metrics}

For each sampling landscape, we used an independent subset of the landscape metrics described above to quantify landscape composition and configuration heterogeneity calculated in FRAGSTATS version 4.2 (McGarigal et al. 2002), as principal components of composition and configuration were not readily interpreted ecologically (Table S2). We chose Shannon diversity index of land-cover types (SHDI) to represent compositional heterogeneity, and total length of edge between land-cover classes (TE) and patch cohesion (COHESION) as relatively independent configurational heterogeneity metrics $(\mathrm{r}<|0.6|)$. We calculated the total coverage of savanna in hectares in the sampling landscape and used it as the predictor to test the alternative habitat amount hypothesis.

\section{Fine-scale vegetation heterogeneity}

At each of our 80 plots (16 landscapes, 5 plots/landscape), we sampled the following structural vegetation features: (1) grass biomass, (2) shrub cover, (3) canopy cover, and (4) canopy height. Every ten meters along $2 \times 50 \mathrm{~m}$ transects, we estimated shrub cover and measured grass biomass, canopy cover, and canopy height with a disc pasture meter (Bransby and Tainton 1977), densiometer (Smit and Prins 2015) and meter stick respectively. To create a single metric of vegetation structural heterogeneity (VSH), we combined the measurements of the vegetation layers by taking the sum of the standardized variances of grass biomass, shrub cover, canopy cover, and canopy height for each plot. Each of these components of vegetation structure is important because savannas are defined as a biome where trees and grass interact, and shrub encroachment has been widely observed in 
savannas (Scholes and Archer 1997; Roques et al. 2001). We standardized variances by rescaling them to have a mean of zero and standard deviation of one. This summed metric was moderately correlated with each of its components and thus weighted each component relatively equally, with correlations of $r=0.39,0.55$, 0.68 , and 0.52 for grass biomass, shrub cover, canopy cover, and canopy height respectively.

\section{Data analysis}

We used linear mixed effects models in the lme4 package (Bates et al. 2014) to model the response of species richness and Simpson's Diversity Index (TD metrics), $\mathrm{FD}$, and PD as a function of landscape composition (SHDI), landscape configuration (TE and COHESION), habitat amount (SAVANNA), and vegetation structural heterogeneity (VSH). We included sampling landscape as a random effect to account for any dependence between plots within landscapes. All explanatory variables were scaled and centered prior to analysis to allow for the comparison of their effects on the response.

We used model selection to analyze the effects of landscape heterogeneity and competing hypotheses on TD (richness and Simpson's diversity), FD, and PD. For each of the four response variables, we tested a candidate set of eight models corresponding to our three competing hypotheses as well as a null model with only the intercept term. We used the following model parameters as well as the additive two-way combinations of uncorrelated parameters to test the effect of landscape heterogeneity on diversity metrics: (1) SHDI, (2) TE, (3) COHESION, (4) SHDI + TE, and (5) SHDI + COHESION. To test the effect of habitat amount on diversity metrics, we created models only containing the amount of savanna (SAVANNA), and to test the effect of vegetation structural heterogeneity on diversity metrics, we built models only containing the vegetation structural heterogeneity metric (VSH). The best models were selected using the Akaike information criterion corrected for small samples sizes (AICc) to determine the strongest predictors of species richness, Simpson's diversity, FD, and PD (Burnham and Anderson 2004). We considered models with AICc values less than the null as plausible models, and considered the model with the lowest AICc value as our best model. Model parameters were determined to be significant if the $95 \%$ confidence interval around the estimate did not overlap zero.

Finally, to determine if landscape heterogeneity, habitat amount, or vegetation structural heterogeneity had effects on taxonomic community dissimilarity, we used a Permutation Multivariate Analysis of Variance (PerMANOVA) utilizing the 
adonis function from the package vegan (Oksanen et al. 2013). PerMANOVA is a non-parametric technique that uses distance matrices to partition variance between samples and permutation to produce a pseudo-F statistic and $p$ value. We used the Bray-Curtis distance matrix calculated earlier and stratified the permutation by sampling landscape to account for our nested design. We did not calculate beta diversity for FD or PD because these metrics are single, aggregated FD and PD values for each plot, such that multivariate response data regarding compositional changes are not available.

To test that spatial autocorrelation was not an issue in our dataset we also calculated the Moran's I Autocorrelation Index for bird species richness and diversity metrics for sampling landscapes in the ape package (Paradis et al. 2004) and found that no metric was significantly spatially autocorrelated.

All statistical analyses were conducted in R statistical software Version 3.2.4. (R Core Team 2000), unless otherwise indicated.

\section{Results}

We recorded 2759 detections of 85 bird species (Table S3). Among the species we detected, we recorded four endemic and two near-endemic species to southern Africa. The number of species recorded within each plot ranged from 4 to 28 with a median number of 15 , while the jackknife estimate of species richness ranged from 7 to 39 species with a median of 22 . The Simpson diversity index ranged from 2.8 to 17.5 with a median of 9.9. Functional diversity z-scores ranged from -2.9 to 1.9 with a median of -0.6 , and phylogenetic diversity z-scores ranged from -3.6 to 1.2 with a median of -1.6 (Table S4). All metrics were relatively uncorrelated ( $r$ $<|0.2|)$ except for the jackknife estimate of species richness and Simpson's diversity, which had a correlation of $r=0.84$. We reported results for both metrics because both of them are commonly considered in biodiversity conservation. The five most commonly detected species were dark-capped bulbul (Pycnonotus tricolor), white-bellied sunbird (Cinnyris talatala), chinspot batis (Batis molitor), red-faced mousebird (Urocolius indicus), and yellow-breasted apalis (Apalis flavida). Each of these species occurred in at least $60 \%$ of the point counts.

\section{Models for TD}

Three candidate models were better than the null model when investigating the effects of landscape composition (SHDI) and configuration (TE and COHESION) on non-breeding bird species richness (Table 1). The top model contained only 
COHESION as a predictor and showed a significant negative effect on species richness (Table 2, Fig. 2a).

\section{Table 1}

The null and competing linear mixed effects models investigating the effects of land-cover diversity (SHDI), land-cover cohesion (COHESION), total edge length (TE), habitat amount (SAVANNA), and vegetation structural heterogeneity (VSH) on bird species richness (jackknife estimator), Simpson's diversity, functional diversity, and phylogenetic diversity

\section{\begin{tabular}{l|l|l|l|l} 
K & AICc & Delta_AICc AICcWt & LL
\end{tabular}}

Taxonomic diversity—-species richness

\begin{tabular}{|l|l|l|l|l|l|}
\hline COHESION & 4 & 548.57 & 0.00 & 0.36 & -270.02 \\
\hline SHDI + COHESION & 5 & 550.33 & 1.77 & 0.15 & -269.76 \\
\hline SAVANNA & 4 & 550.54 & 1.97 & 0.14 & -271.00 \\
\hline SHDI & 4 & 550.70 & 2.14 & 0.12 & -271.09 \\
\hline Null & 3 & 551.27 & 2.70 & 0.10 & -272.47 \\
\hline SHDI + TE & 5 & 552.11 & 3.54 & 0.06 & -270.65 \\
\hline TE & 4 & 553.06 & 4.49 & 0.04 & -272.26 \\
\hline VSH & 4 & 553.41 & 4.85 & 0.03 & -272.44 \\
\hline
\end{tabular}

Taxonomic diversity—Simpson's diversity index

\begin{tabular}{|l|l|l|l|l|l|}
\hline SHDI & 4 & 418.23 & 0.00 & 0.25 & -204.85 \\
\hline SAVANNA & 4 & 419.23 & 1.00 & 0.15 & -205.35 \\
\hline SHDI + TE & 5 & 419.38 & 1.15 & 0.14 & -204.28 \\
\hline COHESION & 4 & 419.43 & 1.20 & 0.13 & -205.45 \\
\hline Null & 3 & 419.45 & 1.22 & 0.13 & -206.57 \\
\hline SHDI + COHESION & 5 & 420.10 & 1.87 & 0.10 & -204.65 \\
\hline TE & 4 & 421.05 & 2.82 & 0.06 & -206.26 \\
\hline VSH & 4 & 421.63 & 3.40 & 0.04 & -206.55 \\
\hline
\end{tabular}

Functional diversity

The models are ranked based on the differences in the cumulative corrected Akaike's Information Criteria (AICc). This table includes the number of estimated parameters (K), the AICc, the difference in AICc with the top model (Delta_AICc), the weight of each model (AICcWt), and the - 2log-likelihood output for each model (LL) 


\begin{tabular}{|l|l|l|l|l|l|}
\hline & K & AICc & Delta_AICc & AICcWt & LL \\
\hline Null & 3 & 228.84 & 0.00 & 0.32 & -111.26 \\
\hline VSH & 4 & 230.06 & 1.22 & 0.17 & -110.76 \\
\hline COHESION & 4 & 230.88 & 2.04 & 0.11 & -111.17 \\
\hline TE & 4 & 230.90 & 2.06 & 0.11 & -111.18 \\
\hline SHDI & 4 & 231.03 & 2.19 & 0.11 & -111.25 \\
\hline SAVANNA & 4 & 231.05 & 2.21 & 0.10 & -111.26 \\
\hline SHDI + COHESION & 5 & 232.95 & 4.12 & 0.04 & -111.07 \\
\hline SHDI + TE & 5 & 233.13 & 4.29 & 0.04 & -111.16 \\
\hline
\end{tabular}

Phylogenetic diversity

\begin{tabular}{|l|l|l|l|l|l|}
\hline SAVANNA & 4 & 247.53 & 0.00 & 0.34 & -119.50 \\
\hline Null & 3 & 248.59 & 1.06 & 0.20 & -121.14 \\
\hline SHDI & 4 & 249.61 & 2.08 & 0.12 & -120.54 \\
\hline SHDI + COHESION & 5 & 250.36 & 2.84 & 0.08 & -119.78 \\
\hline VSH & 4 & 250.42 & 2.89 & 0.08 & -120.94 \\
\hline COHESION & 4 & 250.63 & 3.10 & 0.07 & -121.05 \\
\hline TE & 4 & 250.80 & 3.28 & 0.07 & -121.14 \\
\hline SHDI + TE & 5 & 251.87 & 4.34 & 0.04 & -120.53 \\
\hline
\end{tabular}

The models are ranked based on the differences in the cumulative corrected Akaike's Information Criteria $(\mathrm{AICc})$. This table includes the number of estimated parameters $(\mathrm{K})$, the AICc, the difference in AICc with the top model (Delta_AICc), the weight of each model (AICcWt), and the - 2log-likelihood output for each model (LL)

\section{Table 2}

Parameter estimates $(\beta)$, Standard errors (SE) and confidence intervals of plausible linear mixed effects models using land-cover diversity (SHDI), land-cover cohesion (COHESION), total edge length (TE), habitat amount (SAVANNA), and vegetation structural heterogeneity (VSH) to predict non-breeding bird species richness (jackknife estimator) and Simpson's diversity

Models

$$
\boldsymbol{\beta} \pm \mathbf{S E}
$$

\section{Confidence Interval}

\section{$\mathbf{2 . 5 0 \%} \quad \mathbf{9 7 . 5 0 \%}$}

Significant parameters where confidence intervals do not overlap zero are indicated in bold 

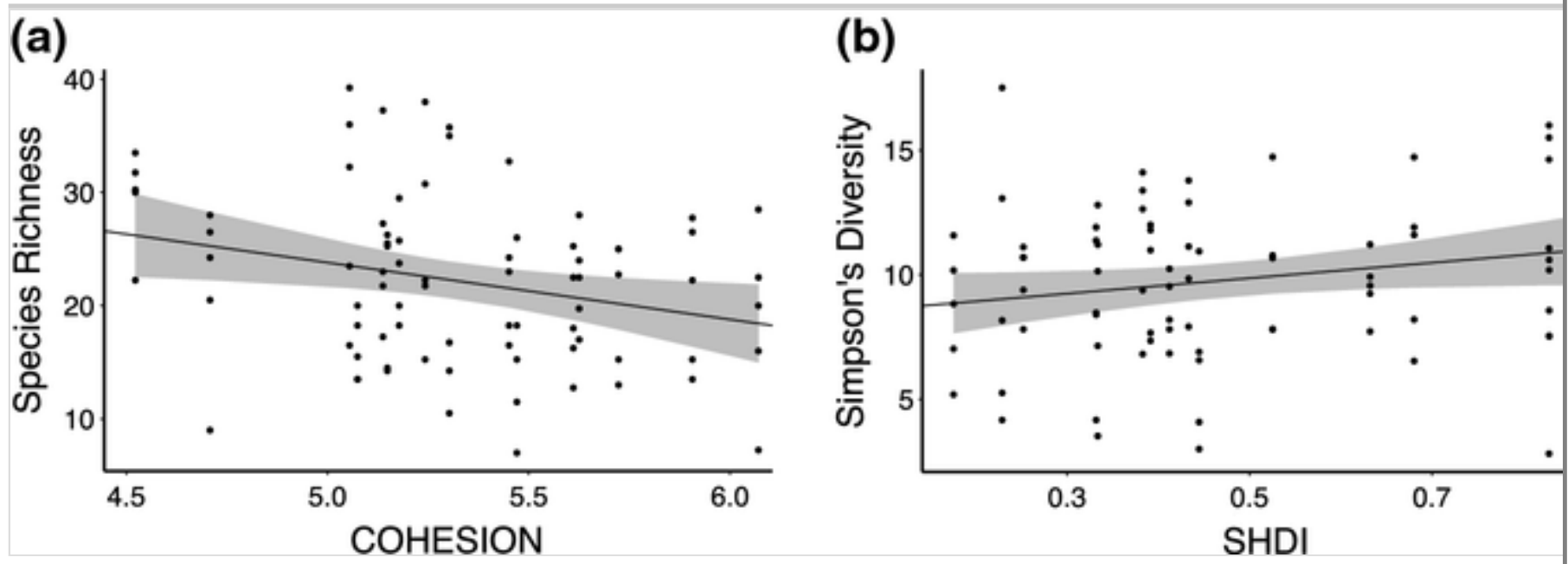

Three models were superior to the null model when modelling the effects of landscape heterogeneity on Simpson's diversity for non-breeding birds (Table 1). The best model contained SHDI as a predictor, but SHDI had a non-significant effect on species diversity (Table 2, Fig. 2b). In the second-best model, i.e. SHDI + TE, SHDI had a significant positive effect on species diversity, while TE had a nonsignificant (negative or positive) effect.

When testing the effects of landscape heterogeneity variables, amount of savanna, and the VSH variable on community dissimilarity, we found that the model of SHDI and the model of SAVANNA significantly affected community composition (Table 3). Additionally, for the model containing SHDI + TE, both parameters had significant effects on dissimilarity (Table 3 ).

\section{Table 3}

Pseudo-F statistics and $\mathrm{p}$ values for significant predictors of taxonomic community dissimilarity

\begin{tabular}{|l|l|l|}
\hline Predictor(s) & pseudo-F & p value \\
\hline SHDI & 4.19 & $<0.0005$ \\
\hline SAVANNA & 6.60 & 0.003 \\
\hline SHDI + TE & 4.29 & 0.009 \\
\hline $\begin{array}{l}\text { Variables include land-cover diversity (SHDI), habitat amount (SAVANNA), and total } \\
\text { edge length (TE) }\end{array}$ & 2.86 & 0.045 \\
\hline
\end{tabular}




\section{Models for FD and PD}

No candidate models were better than the null model when investigating the effects of landscape composition and configuration, habitat amount, and vegetation structural heterogeneity on non-breeding bird FD (Table 1). One model was superior to the null model when modelling the effects of landscape composition and configuration, habitat amount, and vegetation structural heterogeneity on PD for non-breeding birds (Table 1). The model contained SAVANNA, and the variable had a positive but marginally non-significant effect on PD (Table 2).

\section{Discussion}

Our results showed that landscape heterogeneity was the strongest biodiversitygenerating hypothesis for alpha taxonomic diversity (TD), while we found that landscape heterogeneity, habitat amount, and total edge were important for beta taxonomic diversity. Functional diversity (FD) was not explained by any of the hypotheses considered. We found some evidence that phylogenetic diversity (PD) increased proportionately with the amount of savanna, though the parameter was marginally non-significant. This suggests that heterogeneous landscapes alone do not appear to foster all types of diversity equally. We found that higher TD is possible in heterogeneous landscapes, but it is possible that these additional species are not of value if the goal is to promote FD or PD. Consequently, conservation efforts focusing on increasing landscape heterogeneity to promote or maintain TD may not be met with increases in either FD or PD.

\section{Components of landscape heterogeneity}

We found a negative relationship between the patch cohesion index and species richness. The patch cohesion index reported here represented the mean cohesion of all land-cover types. Thus, lower cohesion was related to more complex landscape configuration with more fragmentation. This finding seemed contrary to studies that advocate for increasing habitat connectivity to increase population persistence and recovery from disturbance (Almany et al. 2009; Fletcher et al. 2016). However, at the community-level, species richness can increase with habitat fragmentation, which is often driven by the accumulation of non-specialist species (e.g. Pfeifer et al. 2017). For example, Baz and Garcia-Boyero (1995) found that species diversity of butterflies increased with increasing patchiness (i.e. decreasing cohesion) of forest fragments. In a review of landscape connectivity research, Fletcher et al. (2016) found that connectivity led to more negative community-level responses than other types of responses (e.g. genetic or individual-level responses). Patch cohesion had a stronger effect on species richness than on Simpson's diversity, 
which is consistent with the hypothesis that fragmentation allows for more species to coexist by preventing a single species from dominating an area (Knapp et al. 1999).

Land-cover diversity was the strongest predictor of non-breeding bird Simpson's diversity, albeit it was not always statistically significant (i.e., across all models considered). A possible explanation for land-cover diversity having a stronger effect on Simpson's diversity than species richness is that more evenness in land-cover types promotes more evenness in non-breeding bird species, while species richness is driven by land-cover richness or fragmentation. Land-cover diversity also had a strong effect on community dissimilarity possibly because the greater breadth of resources surrounding savannas allows more species to be present at a large scale, causing more variability in the species across our sampling area (Dunning et al. 1992). In our study system, species richness of ants has been found to be positively related to both compositional and configurational heterogeneity, which is consistent with our results for birds (Reynolds et al. 2018). However, there was a negative relationship between compositional heterogeneity and dung beetle richness (Reynolds et al. 2018). Our work adds to the context of these findings by exploring other responses and dimensions of biodiversity in addition to TD.

We did not observe an effect of landscape heterogeneity on either FD or PD, meaning that species losses over our landscape heterogeneity gradients did not coincide with disproportionate losses of FD or PD compared to a randomly selected species community. Instead, the effect of agricultural intensification or proximity to agriculture on FD may be stronger than the effect of landscape heterogeneity (Tscharntke et al. 2008; Flynn et al. 2009). It is also possible that our sampling landscapes shared many generalist species with similar functional traits, making functional dispersion values similar between sites. We found a stronger effect of habitat amount than landscape heterogeneity on PD, possibly because phylogenetically distinct lineages tend to require less degradation and humanmodification in the landscape (Frishkoff et al. 2014), and loss of those lineages would decrease the phylogenetic mean pairwise distance of communities. We did not include several groups of functionally and phylogenetically distinct birds (e.g. waterbirds, raptors) in our sampling, which may have led to stronger or different patterns.

\section{Landscape heterogeneity versus alternative hypotheses}

We found no support for an effect of fine-scale heterogeneity of vegetation structure on non-breeding bird TD, FD, and PD. The lack of an effect of vegetation structure 
on diversity may have arisen for several reasons. First, the vegetation structural heterogeneity hypothesis originates from forest ecosystems (e.g. MacArthur 1958; Lesak et al. 2011; Mulwa et al. 2012), where bird species may be more specialized to the vertical layers in forests than in savannas. In savannas, heterogeneity arises from different disturbances, such as shrub encroachment (Stanton et al. 2018) altering shrub heterogeneity and fire altering grass heterogeneity (Roques et al. 2001). Additionally, vegetation structural heterogeneity may be more important during the breeding season in terms of providing variation in nesting substrates than in the non-breeding season (Cody 1985). This study took place in the non-breeding season; had we sampled in the breeding season, where the bird community is different (Monadjem 2002), we may have seen a stronger relationship with vegetation structure. However, species richness of other taxa in the region have shown generally similar responses between seasons (Hurst et al. 2013). Results may also depend on the metric used to measure structural heterogeneity, which differs between studies (Tews et al. 2004). It is possible that the structural heterogeneity of a single component of vegetation had an effect on non-breeding bird diversity. However, rather than using one vegetation layer (e.g. canopy height) to measure structural heterogeneity, our metric captured and combined the heterogeneity of each vegetation layer (grass, shrub, canopy). Nevertheless, it is possible that the variables we chose to measure did not account for the variation in vegetation structure at the optimal spatial scale at which birds exhibit responses. Finally, we conducted our sampling during a drought year, which may not be ideal for testing the vegetation structural heterogeneity hypothesis due to reductions in foliage, fruiting resources, and grass biomass, (Scholes and Archer 1997).

Despite a resurgent interest in the role of habitat amount on species diversity (Fahrig 2013; Haddad et al. 2017), the amount of savanna surrounding a sampling landscape was not a relatively strong predictor of non-breeding bird TD or FD. Contrary to the habitat amount hypothesis, TD measures decreased with the amount of savanna. Land-cover diversity was negatively correlated with the amount of savanna $(r=-0.79)$, which is likely the reason this model received some support. As amount of savanna decreased, the amounts of other land-covers increased, which increased species diversity through landscape complementarity (Dunning et al. 1992; Stevens et al. 2003).

Meanwhile, there was a marginally non-significant positive effect of habitat amount on PD. This result may support previous research that human modification of land, such as agricultural expansion and intensification, threatens more evolutionarily distinct species (Frishkoff et al. 2014) because loss of those species would decrease 
the phylogenetic mean pairwise distance of a community. Some families of birds, such as vultures, have been found to be dependent on protected areas, likely due to their sensitivity to disturbance and poaching (Monadjem and Garcelon 2005), and this sensitivity may apply to other families or species. Large, slow-breeding species may rely on large areas of habitat because there may not be enough resources for them to survive in small patches. For example, the trumpeter hornbill, a large frugivore, may need extensive savanna to provide sufficient fruit, and because large body size correlates with traits like lower abundance and higher trophic level, large species may more sensitive to human disturbance (Turner 1996; Newbold et al. 2013). Had we included raptors, waterbirds, shorebirds, and nocturnal birds in our bird community sampling, we may have seen a stronger effect of the amount of savanna habitat on PD. These groups of birds are most in need of conservation and comprise a significant proportion of threatened species (Beresford et al. 2011), making the inclusion of these species in future studies of paramount importance.

\section{Conservation implications}

Rapid land-use change in savanna landscapes is affecting biodiversity (Nix et al. 2013). Broad landscape-scale variables were more influential on non-breeding bird TD, which is important because species-rich communities tend to be functionally redundant, protecting communities from the loss of FD if local extinction rates increase (Carmona et al. 2017). Though heterogeneity may promote more TD, it did not have a strong effect on FD or PD, so it may only be promoting species that are not functionally or phylogenetically unique. Thus, there is still a critical role for large continuous habitat to maintain phylogenetically distinct species. Importantly, our results highlight that bird TD, FD, and $\mathrm{PD}$ responded differently to landscape heterogeneity, habitat amount, and vegetation structural heterogeneity, demonstrating the importance of including multiple dimensions of biodiversity in conjunction with various landscape and habitat measures when designing conservation management strategies. Conservation practitioners should consider which dimension(s) of biodiversity to prioritize when making management decisions. To maximize multiple dimensions of biodiversity, we may need to consider strategies that integrate heterogeneous landscapes with large areas of habitat.

\section{Acknowledgements}

We are grateful to all the field assistants who helped with the collection of the data and to the land owners who granted permission to work on their properties. We also acknowledge considerable support from All Out Africa and the Savanna Research 
Center. This research was funded by a National Science Foundation ISE Grant (No. 1459882 to RAM, AM, and RJF) and the College of Agriculture and Life Science at the University of Florida and the USDA National Institute of Food and Agriculture.

Author Contributions

RAM \& RJF conceptualised the study. AK, MS, CR \& AM collected the data. AK, CR \& RJF analysed the data. AK \& MS led the writing. All authors edited the manuscript.

\section{Electronic supplementary material}

Below is the link to the electronic supplementary material.

Supplementary material 1 (DOCX $30 \mathrm{~kb}$ )

\section{References}

Almany G, Connolly S, Heath D, Hogan J, Jones G, McCook L, Mills M, Pressey R, Williamson D (2009) Connectivity, biodiversity conservation and the design of marine reserve networks for coral reefs. Coral Reefs 28:339-351

Bates D, Maechler M, Bolker B, Walker S (2014) lme4: linear mixed-effects models using Eigen and S4. R Package Version 1

Baz A, Garcia-Boyero A (1995) The effects of forest fragmentation on butterfly communities in central Spain. J Biogeogr 22:129-140

Benton TG, Vickery JA, Wilson JD (2003) Farmland biodiversity: is habitat heterogeneity the key? Trends Ecol Evol 18:182-188

Beresford A, Buchanan G, Donald P, Butchart S, Fishpool L, Rondinini C (2011) Poor overlap between the distribution of protected areas and globally threatened birds in Africa. Anim Conserv 14:99-107

Bransby D, Tainton N (1977) The disc pasture meter: possible applications in grazing management. In: Proceedings of the annual congresses of the Grassland Society of Southern Africa, vol 12, pp 115-118 
Brashares JS, Arcese P, Sam MK (2001) Human demography and reserve size predict wildlife extinction in West Africa. Proc R Soc Lond B Biol Sci 268:2473-2478

Būhning-Gaese K (1997) Determinants of avian species richness at different spatial scales. J Biogeogr 24:49-60

Burnham KP, Anderson DR (2004) Multimodel inference understanding AIC and BIC in model selection. Sociol Methods Res 33:261-304

Cadotte MW (2013) Experimental evidence that evolutionarily diverse assemblages result in higher productivity. Proc Natl Acad Sci USA 110:89969000

Cadotte MW, Dinnage R, Tilman D (2012) Phylogenetic diversity promotes ecosystem stability. Ecology 93:s223-s233

Carmona CP, Guerrero I, Morales MB, Oñate JJ, Peco B (2017) Assessing vulnerability of functional diversity to species loss: a case study in Mediterranean agricultural systems. Funct Ecol 31(2):427-435

Cody, M.L. (1985) Habitat selection in birds Academic Press

Coudrain V, Schüepp C, Herzog F, Albrecht M, Entling MH (2014) Habitat amount modulates the effect of patch isolation on host-parasitoid interactions. Front Environ Sci 2:27

Critical Ecosystem Partnership Fund (2010) Maputaland-Pondoland-Albany Ecosystem profile summary, vol 2016. Critical Ecosystem Partnership Fund, Cape Town

Culbert PD, Radeloff VC, Flather CH, Kellndorfer JM, Rittenhouse CD, Pidgeon AM (2013) The influence of vertical and horizontal habitat structure on nationwide patterns of avian biodiversity. Auk 130:656-665

Cushman SA, McGarigal K, Neel MC (2008) Parsimony in landscape metrics: strength, universality, and consistency. Ecol Indic 8:691-703 
de Lima RF, Dallimer M, Atkinson PW, Barlow J (2013) Biodiversity and landuse change: understanding the complex responses of an endemic-rich bird assemblage. Divers Distrib 19:411-422

DeJong T (1975) A comparison of three diversity indices based on their components of richness and evenness. Oikos 26:222-227

Devictor V, Mouillot D, Meynard C, Jiguet F, Thuiller W, Mouquet N (2010) Spatial mismatch and congruence between taxonomic, phylogenetic and functional diversity: the need for integrative conservation strategies in a changing world. Ecol Lett 13:1030-1040

Dunning JB, Danielson BJ, Pulliam HR (1992) Ecological processes that affect populations in complex landscapes. Oikos 65:169-175

Fahrig L (2013) Rethinking patch size and isolation effects: the habitat amount hypothesis. J Biogeogr 40:1649-1663

Fahrig L, Nuttle WK (2005) Population ecology in spatially heterogeneous environments. In: Ecosystem function in heterogeneous landscapes. Springer, Berlin, pp 95-118

Fahrig L, Baudry J, Brotons L, Burel FG, Crist TO, Fuller RJ, Sirami C, Siriwardena GM, Martin JL (2011) Functional landscape heterogeneity and animal biodiversity in agricultural landscapes. Ecol Lett 14:101-112

Faith DP (1992) Conservation evaluation and phylogenetic diversity. Biol Conserv 61:1-10

Fletcher RJ, Burrell NS, Reichert BE, Vasudev D, Austin JD (2016) Divergent perspectives on landscape connectivity reveal consistent effects from genes to communities. Curr Landsc Ecol Rep 1:67-79

Flynn DFB, Gogol-Prokurat M, Nogeire T, Molinari N, Richers BT, Lin BB, Simpson N, Mayfield MM, DeClerck F (2009) Loss of functional diversity under land use intensification across multiple taxa. Ecol Lett 12:22-33

Foley JA, DeFries R, Asner GP, Barford C, Bonan G, Carpenter SR, Chapin FS, Coe MT, Daily GC, Gibbs HK (2005) Global consequences of land use. Science 
Freedman B (2014) Population growth and global change. In: Global environmental change. Springer, Berlin, pp 571-577

Frishkoff LO, Karp DS, M'Gonigle LK, Mendenhall CD, Zook J, Kremen C, Hadly EA, Daily GC (2014) Loss of avian phylogenetic diversity in neotropical agricultural systems. Science 345:1343-1346

Gislason PO, Benediktsson JA, Sveinsson JR (2006) Random forests for land cover classification. Pattern Recogn Lett 27:294-300

Goldblatt R, You W, Hanson G, Khandelwal A (2016) Monitoring urbanization processes from space: using landsat imagery to detect built-up areas at scale. In: AGU fall meeting abstracts

Google Earth Engine Team (2015) Google Earth Engine: a planetary-scale geospatial analysis platform. https://earthengine-google.com

Goudie A, Williams DP (1983) The atlas of Swaziland. Swaziland National Trust Commission, Mbabane

Gustafson EJ (1998) Quantifying landscape spatial pattern: what is the state of the art? Ecosystems 1:143-156

Haase CG, Fletcher RJ, Slone DH, Reid JP, Butler SM (2017) Landscape complementation revealed through bipartite networks: an example with the Florida manatee. Landsc Ecol 32(10):1999-2014

Haddad NM, Gonzalez A, Brudvig LA, Burt MA, Levey DJ, Damschen EI (2017) Experimental evidence does not support the Habitat Amount Hypothesis. Ecography 40:48-55

Heikkinen RK, Luoto M, Virkkala R, Rainio K (2004) Effects of habitat cover, landscape structure and spatial variables on the abundance of birds in an agricultural-forest mosaic. J Appl Ecol 41:824-835

Hijmans RJ (2016) Introduction to the raster package. R Package Version 2.5-8 
Hockey P, Dean W, Ryan P (2005) Roberts birds of Southern Africa, 7th edn. The Trustees of the John Voelcker Bird Book Fund, Cape Town

Hurst ZM, McCleery RA, Collier BA, Fletcher RJ Jr, Silvy NJ, Taylor PJ, Monadjem A (2013) Dynamic edge effects in small mammal communities across a conservation-agricultural interface in Swaziland. PLoS ONE 8(9):e74520

Jetz W, Thomas G, Joy J, Hartmann K, Mooers A (2012) The global diversity of birds in space and time. Nature 491:444-448

Kembel SW, Cowan PD, Helmus MR, Cornwell WK, Morlon H, Ackerly DD, Blomberg SP, Webb CO (2010) Picante: R tools for integrating phylogenies and ecology. Bioinformatics 26:1463-1464

Knapp AK, Blair JM, Briggs JM, Collins SL, Hartnett DC, Johnson LC, Towne EG (1999) The keystone role of bison in North American tallgrass prairie: bison increase habitat heterogeneity and alter a broad array of plant, community, and ecosystem processes. Bioscience 49:39-50

Laliberté E, Legendre P (2010) A distance-based framework for measuring functional diversity from multiple traits. Ecology 91:299-305

Laliberté E, Legendre P, Shipley B (2014) FD-package measuring functional diversity from multiple traits, and other tools for functional ecology. http://idg.pl/mirrors/CRAN/web/packages/FD/FD.pdf

Lesak AA, Radeloff VC, Hawbaker TJ, Pidgeon AM, Gobakken T, Contrucci K (2011) Modeling forest songbird species richness using LiDAR-derived measures of forest structure. Remote Sens Environ 115:2823-2835

MacArthur RH (1958) Population ecology of some warblers of northeastern coniferous forests. Ecology 39:599-619

McGarigal K, Cushman SA, Neel MC, Ene E (2002) FRAGSTATS: spatial pattern analysis program for categorical maps. Computer Software

Monadjem A (2002) Population densities and community structure of birds in Acacia savanna in the lowveld of Swaziland. Ostrich J Afr Ornithol 73:11-19 
Monadjem A (2005) Association between avian communities and vegetation structure in a low-lying woodland-savanna ecosystem in Swaziland. Ostrich J Afr Ornithol 76:45-55

Monadjem A, Garcelon DK (2005) Nesting distribution of vultures in relation to land use in Swaziland. Biodivers Conserv 14:2079-2093

Mulwa RK, Böhning-Gaese K, Schleuning M (2012) High bird species diversity in structurally heterogeneous farmland in western Kenya. Biotropica 44:801-809

Neumann JL, Griffiths GH, Hoodless A, Holloway GJ (2016) The compositional and configurational heterogeneity of matrix habitats shape woodland carabid communities in wooded-agricultural landscapes. Landsc Ecol 31:301-315

Newbold T, Scharlemann JP, Butchart SH, Şekercioğlu ÇH, Alkemade R, Booth H, Purves DW (2013) Ecological traits affect the response of tropical forest bird species to land-use intensity. Proc R Soc Lond B Biol Sci 280:20122131

Nix H, Mackey B, Traill B, Woinarski J (2013) The nature of Northern Australia: its natural values, ecological processes and future prospects. ANU Press, Canberra

Oksanen J, Blanchet FG, Kindt R, Legendre P, Minchin PR, O'hara R, Simpson GL, Solymos P, Stevens MHH, Wagner H (2013) Package 'vegan'. Community Ecology Package, version 2

Olff H, Ritchie ME (2002) Fragmented nature: consequences for biodiversity. Landsc Urban Plan 58:83-92

Paradis E, Claude J, Strimmer K (2004) APE: analyses of phylogenetics and evolution in R language. Bioinformatics 20:289-290

Petchey OL, Gaston KJ (2006) Functional diversity: back to basics and looking forward. Ecol Lett 9:741-758

Petchey OL, Hector A, Gaston KJ (2004) How do different measures of functional diversity perform? Ecology 85:847-857 
Pfeifer M, Lefebvre V, Peres CA, Banks-Leite C, Wearn OR, Marsh CJ et al (2017) Creation of forest edges has a global impact on forest vertebrates. Nature 551(7679): 187

Pickett S, Ostfeld RS, Shachak M, Likens G (2012) The ecological basis of conservation: heterogeneity, ecosystems, and biodiversity. Springer, New York

Pimm SL, Gittleman JL (1992) Biological diversity: where is it? Science 255:940-941

Poulsen BO (2002) Avian richness and abundance in temperate Danish forests: tree variables important to birds and their conservation. Biodivers Conserv $11: 1551-1566$

Preston FW (1962) The canonical distribution of commonness and rarity: part I. Ecology 43:185-215

Püttker T, Bueno AA, dos Sanots de Barros C, Sommer S, Pardini R (2013) Habitat specialization interacts with habitat amount to determine dispersal success of rodents in fragmented landscapes. J Mammal 94:714-726

R Core Team (2000) R language definition. R Foundation for Statistical Computing, Vienna

Revelle W (2014) psych: procedures for personality and psychological research. R Package Version 1. Northwestern University, Evanston

Reynolds C, Fletcher RJ, Carneiro CM, Jennings N, Ke A, LaScaleia MC et al (2018) Inconsistent effects of landscape heterogeneity and land-use on animal diversity in an agricultural mosaic: a multi-scale and multi-taxon investigation. Landsc Ecol 33:241-255

Roques K, O'Connor T, Watkinson A (2001) Dynamics of shrub encroachment in an African savanna: relative influences of fire, herbivory, rainfall and density dependence. J Appl Ecol 38:268-280

Safi K, Cianciaruso MV, Loyola RD, Brito D, Armour-Marshall K, Diniz-Filho JAF (2011) Understanding global patterns of mammalian functional and phylogenetic diversity. Philos Trans R Soc Lond B Biol Sci 366:2536-2544 
Scholes R, Archer S (1997) Tree-grass interactions in savannas 1. Annu Rev Ecol Syst 28:517-544

Seymour CL, Simmons RE, Joseph GS, Slingsby JA (2015) On bird functional diversity: species richness and functional differentiation show contrasting responses to rainfall and vegetation structure in an arid landscape. Ecosystems 18:971-984

Sirami C, Monadjem A (2012) Changes in bird communities in Swaziland savannas between 1998 and 2008 owing to shrub encroachment. Divers Distrib $18: 390-400$

Smit IP, Prins HH (2015) Predicting the effects of woody encroachment on mammal communities, grazing biomass and fire frequency in African Savannas. PLoS ONE 10:e137857

Smith EP, van Belle G (1984) Nonparametric estimation of species richness. Biometrics 40:119-129

Smith RJ, Easton J, Nhancale BA, Armstrong AJ, Culverwell J, Dlamini SD, Goodman PS, Loffler L, Matthews WS, Monadjem A (2008) Designing a transfrontier conservation landscape for the Maputaland centre of endemism using biodiversity, economic and threat data. Biol Conserv 141:2127-2138

Stanton RA Jr, Boone WW, Soto-Shoender J, Fletcher RJ Jr, Blaum N, McCleery RA (2018) Shrub encroachment and vertebrate diversity: a global meta-analysis. Glob Ecol Biogeogr 27:368-379

Stevens RD, Cox SB, Strauss RE, Willig MR (2003) Patterns of functional diversity across an extensive environmental gradient: vertebrate consumers, hidden treatments and latitudinal trends. Ecol Lett 6:1099-1108

Sweet R, Khumalo S (1994) Range resources and grazing potentials in Swaziland. FAO, Rome

Tews J, Brose U, Grimm V, Tielbörger K, Wichmann M, Schwager M, Jeltsch F (2004) Animal species diversity driven by habitat heterogeneity/diversity: the importance of keystone structures. J Biogeogr 31:79-92 
Tscharntke T, Sekercioglu CH, Dietsch TV, Sodhi NS, Hoehn P, Tylianakis JM (2008) Landscape constraints on functional diversity of birds and insects in tropical agroecosystems. Ecology 89:944-951

Turner I (1996) Species loss in fragments of tropical rain forest: a review of the evidence. J Appl Ecol 33(2):200-209

VanDerWal J, Falconi L, Januchowski S, Shoo L, Storlie C (2014) SDMTools: species distribution modelling tools: tools for processing data associated with species distribution modelling exercises. R Package Version, 1.1-221

Wagner HH, Fortin M-J (2005) Spatial analysis of landscapes: concepts and statistics. Ecology 86:1975-1987

Walther BA, Martin JL (2001) Species richness estimation of bird communities: how to control for sampling effort? Ibis 143:413-419

Watson JE, Dudley N, Segan DB, Hockings M (2014) The performance and potential of protected areas. Nature 515:67-73

Wilman H, Belmaker J, Simpson J, de la Rosa C, Rivadeneira MM, Jetz W (2014) EltonTraits 1.0: species-level foraging attributes of the world's birds and mammals. Ecology 95:2027-2027

Winter M, Devictor V, Schweiger O (2013) Phylogenetic diversity and nature conservation: where are we? Trends Ecol Evol 28(4):199-204

Wittemyer G, Elsen P, Bean WT, Burton ACO, Brashares JS (2008) Accelerated human population growth at protected area edges. Science 321:123-126

Wright HL, Lake IR, Dolman PM (2012) Agriculture-a key element for conservation in the developing world. Conserv Lett 5:11-19 